\title{
La filosofía y la crisis cultural. Una aproximación a partir de la obra de Cornelius Castoriadis
}

William Mina Aragón

Universidad del Cauca, Colombia

(c) $\underset{\mathrm{BY}}{\mathrm{C}}$ 


\title{
La filosofía y la crisis cultural. Una aproximación a partir de la Obra de Cornelius Castoriadis
}

\begin{abstract}
Resumen: este ensayo pretende rendirle un homenaje al filósofo y psicoanalista griego Cornelius Castoriadis en los 20 años de su defunción y es una manera de reintroducir su pensamiento político y cultural en la academia colombiana, ya que, a pesar de su grandeza ha sido poco trabajado en las universidades en Colombia.

Con este ensayo intitulado La filosofía y la crisis cultural, pretendo inscribir el pensamiento de Castoriadis en la "tradición clásica" de la filosofía, viendo su obra e ideas con categorías originales y profundas que elucidan el "ser" y el pensamiento con todo el rigor de los autores -filósofos de quienes se han atrevido a reflexionar sobre todo lo posible. Creo que la filosofía de Castoriadis desde sus categorías madres (magmas, imaginación radical, imaginario social instituyente, lo histórico-social, lógica ensídica; instituido-instituyente, círculo primario de la creación) responden a dicha exigencia-emergencia con lucidez de maestro griego y artista de la polis ateniense.
\end{abstract}

Palabras clave: filosofía, cultura, insignificancia, democracia, autonomía, política, occidente.

\section{Philosophy and the cultural crisis. An approach based on Cornelius Castoriadis' work}

\begin{abstract}
Greek philosopher and psychoanalyst Cornelius Castoriadis in the 20 years of his death and is a way of reintroducing their political and cultural thought in the Colombian academy because, despite his greatness has been little worked in the universities in Colombia.

With this essay titled Philosophy and cultural crisis, I intend to register the thought of Castoriadis in the "classical tradition" of philosophy, seeing their work and ideas with original and profound categories elucidating "being" and thought with all the rigor the authors-philosophers who have dared to think about everything. I think the philosophy of Castoriadis from their categories mothers (magmas, radical imagination, instituting social imaginary, the historical-social, logic ensidic, instituted-institutive-circle primary creation) respond to this demand-emergency lucidly Greek teacher and artist of the athenian polis.
\end{abstract}

Keywords: philosophy, culture, insignificance, democracy, autonomy, political, West.

Fecha de recepción: 30 de marzo de 2017

Fecha de aceptación: 25 de septiembre de 2017

Forma de citar APA: Mina Aragón, W. (2017). La filosofía y la crisis cultural. Una aproximación a partir de la obra de Cornelius Castoriadis.

Revista Filosofía UIS, 16(2), doi: http://dx.doi.org/10.18273/revfil.v16n2-2017007

Forma de citar (Harvard): Mina Aragón, W. (2017). La filosofía y la crisis cultural. Una aproximación a partir de la obra de Cornelius Castoriadis. Revista Filosofía UIS, 16(2), 141-157.

William Mina Aragón: colombiano. Profesor titular del programa de Ciencia Política de la Universidad del Cauca. PhD en Sociología y Ciencias Políticas. Universidad Complutense de Madrid. Miembro del grupo de investigación Actores, procesos e instituciones políticas (GIAPRIP) e investigador Fundación Universitaria de Popayán del grupo Conflicto armado e iniciativas civiles por la paz (CAPAZ).

Correo electrónico: williammina@hotmail.com

* Artículo de reflexión derivado de investigación. 


\title{
La filosofía y la crisis cultural. Una aproximación a partir de la Obra de Cornelius Castoriadis
}

“¿Qué es un gran hombre sino el que posee grandes afinidades, el que se apodera de todas las artes, las ciencias, todo lo cognoscible como su propio alimento?"

(Emerson R. Waldo, 1963, p. 256).

\begin{abstract}
“Filosofar significa entrar en un ágora o una ecclesía intemporal o temporalmente interminable en donde uno encuentra a todos aquellos que han filosofado, significa poder interpelarlos y también dejarse interpelar por ellos... y continuar a través de los siglos, este dialogo de soporte humano indefinido, que constituye el proyecto filosófico" (Castoriadis, 2004, p. 326).
\end{abstract}

\section{Introducción}

No podríamos comprender la reflexión filosófica de Castoriadis sin aquello que él denomina pensamiento heredado, aquella filosofía ontológica del ser como determinación que va de Parménides a Heidegger, que ha olvidado un nivel fundamental del ser como lo es: lo histórico social (imaginario social instituyentecolectivo anónimo capaz de transformarse a sí mismo y transformar la sociedad) y el nivel psíquico del ser (imaginación radical, no funcional, capaz de creación y pensamiento). Si no hay un sentido del ser (Heidegger), si la filosofía no tiene como preeminencia resolver la pregunta por qué hay algo y no nada (Leibniz), si la filosofía no se apuntala esencialmente en dar respuesta a qué fue lo primero que existió (presocráticos), si tampoco es nada más una teoría del conocimiento (Kant), ni un sistema acabado que dice Razón y Realidad son lo mismo (Hegel), si la filosofía no puede adoptar la actitud de los "nuevos filósofos" franceses y norteamericanos que, hechizados por los análisis del lenguaje de Wittgenstein, del Nihilismo de Nietzsche y del "fin de la filosofía" de Heidegger; se debe ir más allá de esos referentes paradigmáticos de cara a encontrar nuevas vías y caminos en medio de las encrucijadas actuales para dilucidar los dominios filosóficos del Antropos en esta era de conformismo generalizado, de la banalidad política, del triunfo de la religión de la publicidad, pero también del pensamiento débil, de la deconstrucción, de la falsabilidad y del postmodernismo. Es en este horizonte de 
pensamiento creador (mundo greco-occidental de la emergencia de la filosofía, la política, la democracia, del proyecto de autonomía) y del "antipensamiento" (de 1950 a nuestros días) (se verá que Castoriadis crea en medio de clausura de las significaciones imaginarias de nuestra época, opuesta a la crítica, una filosofía ontológica) ¿Qué debo pensar del ser? Que no se detiene en un estrato del ser (lenguaje, ética, política), sino que presenta un enfoque magmático de la misma a partir del estudio de la sociedad, el psicoanálisis y las ciencias puras (física, biología, matemáticas).

Más allá del comentario y la interpretación, el pensamiento de Castoriadis responde con originalidad y creatividad a un proyecto de autonomía e institución imaginaria de la sociedad más allá del marxismo, del socialismo y del liberalismo. Hablar de un final de la filosofía es absurdo, pues, significaría, ni más ni menos, que la "muerte" del proyecto de autonomía individual y colectiva. Es a ello a lo que intentaré responder desde la vida y obra de ese ciudadano ateniense que siempre, con asombro, fusionó vida con filosofía de la libertad.

\section{El legado filosófico griego}

Creemos que no es un hecho fortuito que el filosofar, en su acepción "occidental" haya surgido en suelo griego, en un espacio-tiempo fechable y localizable. ¿Qué factores social-históricos permitieron la irrupción de la filosofía como hecho -magmático- singular, allí y no en ninguna otra parte? Responder a esos interrogantes desde el pensamiento de Castoriadis, es dar respuesta a ese ser que es histórico-social. Es elucidar ese ser que pone en cuestión sus instituciones, significaciones y representaciones instituidas y no obstante, es por ese poner en cuestión que él es, la razón por la que Fabio Giraldo y José Malaver han llamado al pensamiento de Castoriadis una ontología de la creación (Giraldo y Malaver, 1997, p.p 11-57).

¿Qué une a una sociedad X? Sabemos que son una serie de "significaciones imaginarias sociales" (Castoriadis, 1998, p. 69; Castoriadis, 2010, pp. 556-564) las que dan sus valores, normas, comportamientos, conductas, símbolos, principios, instituciones, códigos, etc. Sin ellos ninguna sociedad sería posible, pensable y concebible. Esas significaciones son "inmotivadas y afectivas", pues no obedecen a una lógica de causa-efecto, ni al hecho de ser abstractas, las ha creado esa sociedad X, y ellas dan "sentido" y significación" a su existencia en general. Esas significaciones no son "falsas", simple y complejamente son elaboradas por un colectivo anónimo e impersonal que autoconstituye los valores y comportamientos a partir de lo dado a los "individuos" por aquella sociedad. Desde Castoriadis podríamos responder: "Solo en la medida en que acepta sus significaciones e instituciones como incuestionables, ella es representación, sentido y verdad de sí y para sí misma" (Castoriadis, 2004, p. 32). Esa sociedad se ha instituido en 

partir de la obra de Cornelius Castoriadis

la clausura de sus significaciones imaginarias, una apertura de la misma sería imposible, impensable. El rasgo específico, singular, inédito, novedoso, la nueva eidos - forma creada - inventada por los "griegos" en ciudades como: Atenas, Mileto, Efeso, son que van a poner en cuestión, en tela de juicio (lógon - didónai) sus instituciones y representaciones sociales, sus ídolos de tribu. Dar "cuenta y razón", "juzgar y decidir", solo pudiera brotar en Grecia. Con su estilo irónico y burlón que siempre lo caracterizó, "Un Sócrates faraónico es imposible". Por ello compartía la frase de Hannah Arendt: "La imparcialidad nació con Homero" (Castoriadis, 1998, p. 98).

Los antiguos griegos, entre los siglos VIII al IV a.C., inventan un nuevo tiempo social e histórico, como instituyente capaz de romper lo instituido, lo clausurado, lo heterónomo y ser capaz de crear una apertura de interrogación "razonada" que no conoce límite alguno, donde las significaciones "orden", "ley", "pensamiento", "verdad", "ser", "institución", "Dios", son puestas en duda y, no obstante, la sociedad no se desgaja, ni muere al cuestionar en un movimiento abierto los principios - fundamentos (arché) de su auto- constitución como ser - sociedad ${ }^{1}$. ¿Será que Tales de Mileto es la primera subjetividad reflexionante, individuo individualizado - ciudadano, quien se atreve a romper este cerco del ser-como lo que es: mundo - cosmos determinado (peras)?

Antes de responder este interrogante, es necesario precisar que el ser Tales de Mileto sólo es posible en un universo social-histórico del pensar, donde la libertad del mismo es una condición sine qua non de mi existencia; pienso porque no está prohibido, y que no esté cohibido pensar, hace parte del círculo primario de la creación. Ello, presupone que viva en una sociedad autónoma y no heterónoma que ha investido "las diferencias argumentativas" ${ }^{2}$, no las diferencias por diferencias, no otredad por otredad, como un principio filosófico racional. El que la individualidad Tales de Mileto diga el arché es agua, sólo es posible en una sociedad donde la democracia, el libre examen, la opinión y donde el debate en torno a la materia, al cosmos y al ser no se han clausurado. Lo que se tiene aquí es una apertura del pensamiento y del ser como interrogación abierta, sin fin, llena de aporías (Castoriadis, 2004, p. 307).

\footnotetext{
${ }^{1}$ Los griegos, al valorar autonómicamente su cultura y la de los otros, crean la historiografía; ese es el mérito de Heródoto y de Tucídides. Ellos empiezan a dar una explicación objetiva de los hechos. En el texto "Lo que hace Grecia" (de Homero a Heráclito) Castoriadis, desarrolla dicha idea.

${ }^{2}$ El concepto de sociedad abierta-cerrada que utiliza Karl Popper es parecido al de autonomía-heteronomía propuesto por Castoriadis como categorías históricas y sociales propias del imaginario occidental ateniense, griego... La sociedad cerrada es opuesta a la libertad, "a la democracia, a la justicia, expresando lo que es natural, lo funcional y lo trivial de las sociedades tradicionales". La sociedad abierta es apertura y la cerrada es clausura. En palabras de Castoriadis, sería el paso del "cerco cognitivo de la institución heterónoma para dar paso a la apertura filosófica, asunto que me permite decir así es o no es, y por qué motivos, razones y circunstancias, esto es válido de derecho y no de hecho.
} 
En fin, el que Tales de Mileto critique las teogonías de Hesíodo, en el lenguaje de Castoriadis es pensable en la medida que el propio pensamiento del Milesio se desenvuelva en una lógica de co-presencia, co-nacimiento y copertenencia recíproca, como una gran cadena del ser-magmático, entre: sociedad democrática, subjetividad reflexionante, tiempo libre, espacio para la discusión de las leyes, ciudadano responsable, etc. En sí, el círculo primario de la creación solo es concebible si ésta sociedad ha asumido estos valores como hecho social e histórico.

Para Castoriadis, la filosofía no debería empezar con Hesíodo y los presocráticos a secas ${ }^{3}$. ¿Cuál es el mérito de ellos? Demócrito ocupa un emplazamiento especial para Castoriadis, pues, para él, las instituciones, el lenguaje, el derecho, son producto de las convenciones humanas y no tabúes naturales. El "gran Demócrito" de la mortalidad de las creaciones humanas, pero sobre todo porque él diferencia, distingue entre physis-nomos. En las cosas del nomos, de los hombres, no intervienen las leyes superiores (extrasociales); el propio nomos es el principiofundamento de la ley, de la autoinstitución-autoconstitución de la sociedad, ésta es fundamento de sí misma. El ser del nomos de la sociedad es histórico. Es porque la sociedad es capaz de autotransformarse, de autoalterarse, de ser-otra y porque la sociedad griega se auto-constituyó como imaginario radical social e imaginario radical de sus individuos-psique-colectividades como nuevas formas del ser-sociedad y del imaginario filosófico, político y ontológico.

Al interrogante presocrático ¿Qué fue lo primero que existió?, no hay respuesta, pues, Castoriadis va a romper la lógica-ontológica que va a inaugurar Parménides, el gran lógico y teórico del ser como determinación (peras). "El eleata dice que el ser es y el no-ser no es. No dice nunca que hay una primera-causa, hay sí un elemento constitutivo de lo real, un principio 'trascendental' al universo físico y no "inmanente" al mundo-del ser-ente-total. Ningún pensador griego va a ser tan ingenuo como para creerse que las cosas, la naturaleza, la significación, la representación, el mundo, vienen de la "nada" absoluta ${ }^{4}$.

\footnotetext{
Olof Gigon cree que al primer hombre que debemos darle el nombre y apellido de filósofo es a un poeta: Hesíodo, pues éste, al exponer su extensa genealogía de los dioses llega a preguntarse "inconscientemente" por tres conceptos capitales de la filosofía más allá de lo que las "musas" puedan decirle como no pasaba en el mundo homérico: la verdad, los orígenes, una teoría del todo.

${ }^{4}$ Incluso en la ontología de Aristóteles, el "motor inmóvil", como causa eficiente, es intrínseco a la producción del mundo de las formas. Tampoco el demiurgo de Platón "crea" a partir de la "nada" sino de sí-mismo, de su ser-cuerpo-espacio-propio.

En la astrofísica contemporánea desde que se descubrió el big-bang, se habla de una historia del universo no a partir de la "nada" sino de un "vacío cuántico creador" no pasivo (sin tiempo-espacio), Ileno de toda potencialidad para hacer brotar todas las partículas posibles. Hay que aclarar que el big-bang no fue lo primero que existió, es, más bien, un acontecimiento singular en ilimitados números de universos, pues la creación, la existencia es un "ser" sin comienzo ni final. Sostengo que el momento creador siempre está
} 
Como nunca pudieron establecer un momento cero para la aparición de los seres, del ente, de la "creación" en general, es que un autor como Parménides, entre los presocráticos, hace del ser siempre existente, siempre determinado. Heráclito dirá que: "el universo es un fuego eternamente vivo que, según medida, se enciende y se apaga", que "el universo es, fue y será" (García, 1970, p. 30). Sí, ya sabemos que es el ser: creación, tiempo, indeterminación, surgimiento de nuevas determinaciones; entonces, iqué puede ser la nada? Respuesta: El no tiempo, el caos, la indeterminación, lo sin-fondo, el abismo, lo informe. Creo que la razón por la cual Castoriadis, en su obra póstuma La creación humana, hace una periodización filosófica de Homero a Heráclito, es porque es el paso del giro mitológico al giro humano, antropológico ${ }^{5}$.

Aquí también las similitudes con el autor de La Sociedad abierta y sus enemigos no se hacen esperar, pues, para Popper, Heráclito es iniciador del filosofar en la medida en que "procuró la búsqueda de la mejor explicación desde la razón" (Popper, 1985, pp. 181-184). El pasó de Homero a Heráclito, es el de la clausura seudo-religiosa, cerco cognitivo de la institución, al despliegue de la razón crítica, a la interrogación razonada en un espiral incesante para poner en cuestión a mi antecesor filosófico, ya se trate de Anaxímenes frente a Tales, Heráclito frente a Parménides, Anaximandro frente a Empédocles. Ya se trate de la forma: Nous, apeirón, logos, aire, fuego, tierra, el movimiento reflexivo del pensamiento no se detiene. Es en este sentido, que hay "una primera invención de la filosofía entre los pensadores pre-socráticos que Tales, el milesio inaugura, una ontología del ser llena de aporías y paradojas (ser-devenir; verdadero-falso; caos-orden; nomos physis)" (Castoriadis, 1998, p. 68).

Según Castoriadis, Platón y Aristóteles son pensadores del siglo IV, por consiguiente, no de la creación de la democracia. Lo paradójico es que estos dos titanes del espíritu griego van a emerger cuando la polis ateniense está en descomposición y decadencia. En este aspecto, Castoriadis coincide con Jaeger, en ver en el siglo $\vee$ el gran siglo de la paideia, de las artes, de la cultura espiritual, del humanismo, "Aunque las grandes formas de la poesía, la tragedia y la comedia, que habían puesto su sello al siglo VI, siguen cultivándose con arreglo a la tradición y encuentran sus representantes en un número asombroso de poetas estivales, el aliento poderoso de la tragedia se apaga, la poesía pierde su poder de dirección de la vida espiritual" (Jaeger, 1965, p. 385).

\footnotetext{
presente; en el cristianismo esotérico elevado, identifican esto como el Verbo o la mente contemplándose a sí misma; en las tradiciones filosóficas orientales, se llega a este vacío ilimitado-suyanta por percepción interior, intuición, yoga, meditación. En Oriente, toda ontología termina cuando el ser descubre en su interior que el yo superior y la Mónada son uno indivisible. Ver mi texto El pensamiento afro: más allá de oriente y occidente. Y Ken Wilber. Los tres ojos del conocimiento, pp. 13-19.

${ }^{5}$ Ese mismo giro lo verá Castoriadis en su lectura de Esquilo y Sófocles. Mientras el primero con su Prometeo Encadenado queda preso del reino mitológico, el segundo, con su Antígona pasa a la interrogación sin fin, a los dominios del Antropos, a la interrogación democrática, a llevar la filosofía a la ciudad.
} 
El siglo V ateniense, con toda justicia ha sido denominado el "Siglo de oro de Pericles" por la pléyade creadora de sus poetas, filósofos, historiadores, científicos, artistas, quienes legarán a la posteridad ideas, obras, formas y "aporías", sobre las cuales aún hoy seguimos debatiendo. Este hilo es la materialización viva de la democracia directa en la polis, en el ágora, en la ecclesia; era el siglo del espacio público-público donde el poder instituyente pudo poner en cuestión todas las instituciones y representaciones sociales. Si el nomos es tal ley, justicia, verdad, es creación humana, ello implica que es convencional, arbitrario. He aquí la libertad de pensamiento que va a enfrentar los trágicos (Esquilo-Sófocles); a los filósofos (Heráclito-Parménides); a los líderes políticos (Temístocles-Aristídes); (PericlesCleón). Esa misma libertad de juicio y examen argumentativo no impedirá que Aristófanes se burle de la democracia, que arremeta contra Sócrates y que deje mal parado a Eurípides. Nos acercamos a la debacle del siglo V, cuando:

- "El imperialismo" Ateniense se apaga.

- La guerra del Peloponeso finaliza y Esparta vence a Atenas en el año 404 a.C.

- Los treinta tiranos llegan al poder, incluido Critias, quien había sido discípulo y amigo de Sócrates.

- Cuando se da el juicio de Sócrates.

Estos hechos marcan los signos de la descomposición de la polis ateniense, de sus instituciones y la retirada de la crítica-crítica "racional". Es justamente por defenderla que Sócrates prefiere morir. Sócrates defiende "el derecho" y no "el hecho", cuestiona los usos del poder instituido, las costumbres de lo heredado por la tradición; llámese, saber, conocimiento, verdad, justicia. Sócrates bebe cicuta porque "es incapaz" de concebir una vida sin indagar, sin preguntar, sin cuestionar. He aquí el alcance, la significación de Sócrates como "el último ciudadano-filósofo de la polis", al decir de Jaeger (Jaeger, 1965, p. 456; Castoriadis, 1993, p. 126).

Llegamos así a la época de Platón, al siglo IV, a ese momento que Hegel describió con aquella frase mágica: "El búho de Minerva sólo vuela cuando ha caído la noche". ¿En qué consiste la grandeza de Platón, para Castoriadis? No sólo por haber retomado las grandes aporías-paradojas de los presocráticos, sino en el hecho de que su pensamiento sea una interrogación sin fin, donde nunca las encrucijadas, los enigmas del ser ente-total, se cierran y siempre vuelven sobre el propio pensamiento sin "Fundamentarse en nada". El Platón que interesa a Castoriadis no es el filósofo que se retira de la polis, el hombre sumido en la "caverna", el que interpreta a sus adversarios a su antojo, no el filósofo-rey antidemocrático y quien santifica lo "real", sino el filósofo-pensador que desde su filosofar en forma de diálogo re-inaugura la reflexionalidad sobre todo lo pensable sin nunca dar respuesta acabada del ser, del ente, de todo aquello que amerita reflexión, elucidación: la psique, la ciudad, la justicia, Dios, la verdad, el lenguaje, lo real, la ciencia; en una palabra, el conocimiento ontólogico en general, y esto causa asombro, curiosidad por estudiarlo, "todo" es por ello que "querámoslo o 
no somos platónicos ${ }^{6}$ (Castoriadis, 2001, p. 170). En cuanto a la interpretación de Platón, también Castoriadis difiere de K.R. Popper. Para el autor de La sociedad abierta y sus enemigos no sólo es "el más grande, dotado y profundo de todos los filósofos" (Popper, 1994, p. 226), sino "el discípulo traidor de su Maestro Sócrates, el inspirador de una institución que animó la inquisición, el filósofo-rey, sabio, ideólogo del totalitarismo, el enemigo de la sociedad abierta" (Popper, 1985, pp. 140-157, 167-195).

Para Castoriadis, el hecho de haber Platón sugerido que los "filósofos" deberían gobernar y presuponer una "élite que sabe". Es lo que podría llamarse "la torsión platónica" al creer que puede haber episteme de la praxis política cuando en realidad lo que hay es doxa, opinión. Este giro en su pensamiento político no da pie, ni argumentos sólidos para tildarle de ser "totalitario". Para Castoriadis es Vladimir Lenín el autor de esta creación monstruosa.

¿Qué Aristóteles es el significativo para Castoriadis? El que históricamente está ubicado geográficamente en el siglo IV, pero en el ámbito de la reflexión política está en el siglo $\mathrm{V}$, ya que hace pensamiento más del nómos que de la physis,

\footnotetext{
${ }^{6}$ Antes del filósofo-matemático A.N. Whitehead (1861-1947) dijera que la filosofía: "sólo consiste en hacer pies de páginas al lado del Platón, el poeta-filosofo norteamericano Emerson (1803-1882) sostuvo antes lo mismo: De Platón proceden todas las cosas de las que todavía escriben y discuten pensadores, aún los hombres más grandes sufren cierta disminución por la desgracia ipuedo llamarla así? De haber llegado después de ese generalizador que agota todos los temas. San Agustín, Copérnico, Newton, Boehme, Swedenborg, Goethe, son igualmente sus deudores y no hacen otra cosa que glosar lo dicho por él. Platón es la filosofía y la filosofía es Platón (Emerson, 1963, p. 249).
}

Aclaro que todo lo que ve Castoriadis como "utopía, metafísica, mitológico, es lo que yo reivindico en él. Mi Platón es el místico, el de la encarnación del alma, el que habló de la Atlántida, el del reino de Cronos, el del rey-filosofo gobernante, el de la idea del bien como la suprema, el que nos dice que conocer es reminiscencias, pero no lo ve con el ojo del intelecto sino con el ojo del espíritu, quizás fue este "ojo" el que le hizo falta percibir a Castoriadis y a los críticos de Platón, que no vieron en él a un iniciado espiritual-divino. Quizás filósofos como Platón, San Agustín, Apolonio de Triana, el mismo Kant y otros, escribían en tercera dimensión, pero sus ideas estaban expresadas en otros planos no tridimensionales del ser. Creo que es lícito articular filosofía con misticismo, lo apócrifo con la ciencia, de lo contrario no nos podríamos explicar por qué en el mundo moderno un científico puro, como Einstein, leyó con provecho La doctrina secreta, de la filosofía esotérica H. B. Blavatsky. ¿Cómo explicarnos que el mismo Einstein haya dialogado creadoramente con Tagore? ¿Cómo elucidar que Krisnamurti haya entrecruzado pensamientos con el físico teórico David Bohm, físico cuántico que Castoriadis leyó con provecho? Pensadores, maestros como Paul Brunton y Ken Wilber le hubiesen enviado una misiva imaginaria: "tienes demasiada sabiduría, pero te equivocaste, porque tu ontología estuvo lejos de Dios. A ti, como a Hegel, Spinoza, Marx, Nietzsche y otros, les hizo falta un maestro. Kant, Platón, Aristóteles, no tuvieron necesidad de ellos, porque miraron con el ojo de la contemplación. Ver: Ken Wilber ("cuestiones cuánticas", escritos místicos de los físicos más famosos del mundo. Y Kant y el más allá"). 
el estagarita que descubre la "imaginación" en el tratado del alma, diciéndonos que "el alma nunca piensa sin fantasmas". El creador del Liceo, el "demócrata" que somete los asuntos humanos al nomos, a la convención a lo contingente, a lo arbitrario. No, el Aristóteles que los árabes -Avicena y Averroes- interpretan desde la lógica, la metafísica y la moral, pero que se guardan silencio sobre la interrogación filosófica-ontológica-política de su obra.

\section{El pensamiento filosófico moderno y el proyecto de autonomía}

La interrogación filosófica reaparece entre los siglos XII y XIII, después de su adormecimiento teológico de más de diez siglos cuando, a partir del "Nominalismo" (Guillermo Occan y Duns Escoto), empiezan a criticar las representaciones instituidas y las significaciones imaginarias de la fe, la verdad revelada y la ontología religiosa instituida del papado, de los emperadores y de los padres de la iglesia. Los movimientos comunales y las aspiraciones de la protoburguesía al auto-gobierno expresan un imaginario social-político radicalmente nuevo con relación a los del imperio, la realeza o el régimen feudal (Castoriadis, 1997, p. 120).

El poder auto-reflexivo del imaginario moderno permitirá la "Constitución de Occidente" a partir del siglo XIII con el renacimiento, el humanismo y posteriormente la ilustración, la enciclopedia, el capitalismo y su imaginario pseudo-racional a todos los dominios humanos. Este capitalismo lleva la técnica, la racionalidad y la burocracia al extremo. La imaginación filosófica en las obras de Kant y Hegel expresan la mayoría de edad de la "razón pura" y del "espíritu absoluto" en un universo donde aparentemente las representaciones sociales del poder y del Estado se han divinizado. El imaginario moderno universaliza la democracia, critica la propiedad y el consumo, enfrenta el proyecto moderno del romanticismo al racionalismo, y radicaliza el "proyecto de autonomía individual y colectiva" en la "revolución" americana (1781), (la Revolución Francesa 1789) a través del movimiento obrero y del marxismo.

A partir de 1920-1950, es decir, el período comprendido entre la primera guerra mundial (1914-1918) y la segunda (1939-1945), el ascenso nazista de Hitler al poder, del totalitarismo stalinista, ofuscan el proyecto de autonomía por ser enemigos de la democracia y la libertad. En medio de esta clausura de la significación política, el imaginario radical social y la sociedad instituyente no se conforman con aceptar la hegemonía de las representaciones sociales y se hacen movimientos de resistencias por otro ser-sociedad en las revolución húngara (1956), la Primavera de Praga (1968), el Mayo Parisino (1968) y en una serie de rebeliones y movimientos sociales estamentarios (mujeres, jóvenes, ambientalistas). Cuando el imaginario social, después de 1920-1950, deja de cuestionarse el magma de significaciones instituidas por el capitalismo, se adormece el proyecto 
de autonomía; incluso la imaginación cultural, política científica de sus creadores entra en una fase de letargo. Es en este ambiente de agotamiento cultural (Castoriadis, 1987, pp. 12-19); de esterilidad política (Castoriadis, 1997, pp. 17 34); de privatización (Castoriadis, 1993, pp. 12-22) de conformismo generalizado e insignificancia (Castoriadis, 1997, pp. 103-127), de banalidad, de imaginación e imaginario en la encrucijada (Castoriadis, 1999, pp. 92- 112) que vamos a inscribir la creatividad magmática de lo que desde la "ontología de la creación" (Giraldo, Malaver, 1997, pp. 11-56), de Cornelius Castoriadis, podríamos Ilamar un proyecto de elucidación-creación filosófica.

\section{Castoriadis: La reflexión filosófica y el imaginario cultural}

¿Cómo re-define Castoriadis la filosofía? ¿Cómo re-inventa la tarea del filosofar? Para él, la filosofía no gira en torno a "qué fue lo primero que existió, o qué es el ser, por qué hay "algo" en vez de nada -preguntas secundarias. Hay, según el pensador ateniense, una pregunta primerísima que "condiciona" "todas las anteriores": "¿Qué debo pensar del ser, de la physis, de la polis, de la justicia, etc., y de mi propio pensamiento? (Castoriadis, 1993, p. 124). ¿Qué es lo "original en esta elucidación? Creatividad profunda, pues, antes que saber qué es el ser, debo presuponer que "yo" como subjetividad reflexiva exista y viva en una sociedad auto-reflexiva-autónoma y no heterónoma- que me permita decir sí o no con conocimiento de causa, es decir; por qué razones debo pensar que ello es así. Seré más claro, no nos podríamos preguntar qué fue lo primero que existió, o porque existe la cosa en vez de la no-cosa, en una sociedad que me prohíba hacerme esas preguntas, características propias de una sociedad heterónoma.

Todo arte de preguntar presupone el "pensamiento libre" en medio de la clausura de la significación instituida en torno al propio pensamiento, alrededor de la verdad, del ser, del origen, de la cosa, y del mundo histórico-social de instituciones: Poder, ley religión, moral, Estado. Más claro todavía, antes de hacerme cualquier pregunta ontológica sobre qué es el ser y si éste tiene algún sentido -Heidegger-, es menester precisar que aquella/esta sociedad haya "fabricado" ciudadanos individualizados -y no zombis- donde toda pregunta sea lícita hacerla en un movimiento continuo, sin fin de interrogatividad, por qué, cómo, de qué manera esta ley-institución- representación-significación es válida de Derecho y no de hecho.

He aquí porque para Castoriadis existe una co-presencia, co-significación entre el nacimiento de la filosofía, la democracia y la política. Son términos solidarios porque los tres brotan en el mismo movimiento de interrogación y cuestionamiento crítico: la democracia como régimen de auto-institución- autogobierno de la colectividad por la colectividad, la política como proyecto de autonomía individual-colectivo, la filosofía como autoreflexividad del pensamiento sobre el 
pensamiento, en sí, ¿qué debo pensar de esta representación? ¿Por qué estas leyes nos convienen? ¿Por qué estas instituciones son deseables para la mayoría? Aquí surge una triple creación ontológica, "auto-poética", porque el pensamiento en su lid con la clausura del pensar siempre va a ser - auto-posición de una nueva forma, modelo de una nueva creación filosófica de este ente singular, original que no tiene nada que ver con la anterior ni que es una mera casualidad ni imitación combinatoria de elementos y conjuntos; pues, la nueva significación-imaginaria filosófica (verdad, pensamiento, sujeto, cosa, realidad) es otra desplegada como creatividad de la imaginación radical individual y del imaginario social colectivo.

En el ámbito político, también tenemos la emergencia auto-poética de nuevas determinaciones del ser-sociedad, no instituida sino auto-instituyente a través del imaginario radical instituyente para auto alterar la ley-institución. En la esfera democrática el poder radical auto-instituyente del colectivo anónimo e impersonal para hacer-ser del nomos convencionalidad- otra, jamás se detiene, siempre emergerá no lo mismo sino lo otro: la forma otro pensar, el eidos-nuevo otra ley, la otra creación del demos. Desde Castoriadis tendríamos que preguntarle a Heidegger ipor qué su reflexión sobre los griegos olvida la psique, la política, el eros, centrándose sólo en el sentido del ser y en algunos aspectos del ente? Será que, como postuló el mismísimo autor de El ser y el tiempo, en su libro Tiempo y Ser (Heidegger, 1999, pp. 77-93), ihemos llegado al final de la filosofía en la época presente de la tecnociencia? No, porque mientras haya hombre habrá reflexión, habrá filosofía, habrá movimiento autoreflexivo. Cree Castoriadis que la filosofía y tarea del pensar, incluso, a partir de "el último Heidegger no es otra cosa que el comentario y la interpretación al cuadrado". Una verdadera filosofía jamás debe ser comentario, ni análisis hermenéutico, ni historia filosóficoacadémica, sino la exposición crítica de un pensamiento propio, original a partir de las aporías centrales que ese pensamiento teórico suscita, trátese de los cuatro grandes de la filosofía en Occidente Platón-Aristóteles, Kant-Hegel o de cualquier otro pensador, Descartes-Spinoza; Husserl-Heidegger. Una de las actividades del filosofar es hacer una filosofía de lo histórico-social, y no una historia de la filosofía a secas basada en la "deconstrucción de los textos del pasado".

Barrunto que la obra lucida de Castoriadis, desde sus ideas madres (magma), lógica poética-imaginaria, ser histórico-social, e imaginación radical creadora, abre caminos y horizontes insospechados para dicho proyecto. Nuestra época no sólo es banal por la exposición seudo-racional del capitalismo-global que irresponsablemente está uniformando al planeta a nombre de la religión del mercado y de pamplinas llamadas mercancías, sino que los "grandes enigmas de la filosofía o la pasión" por resolver esos problemas graves y urgentes (Popper, 1994, p. 228) tienen a desaparecer en complicidad con filosofías débiles, posmodernas, en medio de un eclecticismo pusilánime y barato donde "todo vale" y todo es "falsable". Si todo vale, el trabajo de reflexión filosófica desaparece. Si todo es "falsable" no puedo demostrar cuando surge la invención creativa para decir si 
una teoría es nueva o no. El espíritu del postmodernismo es de tolerancia, el del respeto y de las diferencias por las diferencias a secas. Si aceptamos ello, el trabajo de la subjetividad reflexionante y de su imaginación radical creadora se esfuma en medio de la heteronomía y de la clausura de las significaciones imaginarias sociales en las que vivimos. Detrás del postmodernismo está el individuo pasivo-masael ciudadano televisivo que acepta sin cuestionar lo que ve-oye-siente $y$, sobre todo, que ha dejado de cuestionarse las representaciones sociales del imaginario capitalista (seudo-democracias-oligarquías), donde lo más grave es "la clausura del proyecto de autonomía individual y colectivo. Es por ello que Castoriadis ha dicho: El valor del "postmodernismo" como teórica es que refleja servilmente y, por lo tanto, fielmente, las tendencias dominantes. Su miseria es que sólo provee una simple racionalización, tras una apología que se quiere sofisticada y no es más que la expresión del conformismo y la banalidad (Castoriadis, 1993, p. 21).

- No sólo debemos salvar, reinstituir, reinventar el trabajo filosófico de las "imposturas intelectuales" ${ }^{7}$ (individualismo, deconstrucción, postmodernidad, sino también, de herencias limitadas como la que inauguró Wittgenstein de reducir la esencia de la filosofía a solo un enteestrato del ser: El lenguaje ${ }^{8}$; aunque en la institución imaginaria de la sociedad el investimento del lenguaje juega un rol fundamental por el poder de significar de la lengua específica en tanto código-signo, no podemos limitar la complejidad de la elaboración técnico-filosófica al mundo de las significaciones más.

Aunque las artes estén regidas por el "precio" y no por el "valor", aunque no seamos creadores culturales -de paideia- en el sentido ateniense del término, aunque el dominio pseudo-racional de la tecno-ciencia infeste toda esfera humana; aunque la filosofía se ejerza cada día menos, la tarea de lo que debo pensar y cómo actuar en una sociedad que se desgaja en fragmentos, es la tarea a

\footnotetext{
Los análisis críticos de Castoriadis a las "modas francesas", aquellas que infestaran la vida parisina desde los años 60: Estructuralismo, las filosofías del deseo, el individualismo, se vieron fortalecidas en el lenguaje de la ciencia en 1999 cuando los físicos Alan Sokal, Jean Bricmont, publicaran "imposturas Intelectuales", donde autores como Lacan, Deleuze, Derridá, Serres, Lyotard, resultan mal librados al tratar de impresionar al público no científico e introducir vagamente conceptos de ciencias experimentales puras en las ciencias sociales. Véase: Bricmont. J. y Sokal, A. Imposturas intelectuales.

${ }^{8}$ A propósito de los puzles de Wittgenstein, por el pretendido uso erróneo del lenguaje del cual se derivan todos los problemas filosóficos y la esencia de la misma, el físico inglés Stephen Hawking en su historia del tiempo, nos dice: "En el siglo XVIII, los filósofos consideraban todo el conocimiento humano, incluida la ciencia, como su campo, y discutían cuestiones como ituvo el universo un principio?, sin embargo, en los siglos XIX y XX, la ciencia se hizo demasiado técnica y matemática para ellos, y para cualquiera, excepto para unos pocos especialistas. Los filósofos redujeron tanto el ámbito de sus indagaciones, que Wittgenstein, el filósofo más famoso de este siglo, dijo: La única tarea que le queda a la filosofía es el análisis del lenguaje. iQué distancia, desde la gran tradición filosófica, de Aristóteles a Kant! Breve historia del tiempo, (Hawking, 1988, p. 223).
} 
la que una verdadera filosofía hoy tiene que enfrentarse. Quien se llame filósofo "de hecho y no de palabra" no puede decir, yo me dedicaré a especializarme en esta área del saber porque no lo puedo abarcar todo.

Sabemos que Castoriadis, más allá de cualquier sistema absoluto intenta desde su "complejidad ontológica" (Giraldo, Isaza, 2003, p. 55) y más allá de las pseudolimitaciones del conocimiento unilateral y parcelario, elabora un pensamiento del ser-ente-total desde la imaginación filosófica, demostrándole al pensamiento débil, a la de-construcción, a la filosofía analítica y también a Milán Kundera que todavía puede hacer un trabajo creador, originario, inaudito, elucidador dé todo lo pensable ${ }^{9}$ : lo viviente, lo humano, lo psíquico y lo histórico-social, que de razón y cuenta de la totalidad de la existencia y que responda por la emergencia del Homos-Sapiens-Sapiens en esta "tierra patria" que no hemos creado, pero que estamos destruyendo vilmente.

Un trabajo de elucidación filosófica deberá responder no a un estrato del ser (la política, el lenguaje, la ciencia, el conocimiento, la metafísica, la lógica), sino del ser-ente-total diversificado en el "en-sí y el para sí" a través de una serie magmática de estratos diferentes pero comunicables. "De este ser-así, no podemos estrictamente decir nada, salvo que deba ser que permita precisamente la existencia contigua de lo viviente en su interminable variedad (Castoriadis, 1992, p. 126).

La imaginación radical individual que es creadora de formas, eidos-otros (la subjetividad reflexionante, el pensamiento propio, el arte, lo bello, la imaginación científica y lo imaginario social-histórico como instituyente colectivo anónimo de autoalteración-autotransformación-autocreación social definen la originalidad, profundidad y creatividad inaudita y singular de la obra magmática del pensador ateniense que cuando reflexiona sobre lo pensable lo hace multidimensional y solidariamente, como en las grandes obras de filosofía del pasado y de pensadores llamados clásicos. Creo que es por banalidad hermenéutica, que Castoriadis pasa desapercibido a todos aquellos filósofos-autores laureados hoy por la publicidad y el mercado, justo cuando elabora sus ideas-madres contra ellos.

Así como para Platón "el origen de la filosofía estaba por el asombro", por el amor a la sabiduría (Platón, 1963, p. 209), de Castoriadis podríamos decir que la tarea del pensamiento se apuntala allí. No comentar, ni asumir pasivamente los entes del ser-total, sino elucidad con creatividad en cada uno de ellos (ciencia, sociedad, política, política, psicología, economía) a partir de unas categorías madres (magmas, imaginación, imaginario e histórico-social).

\footnotetext{
${ }_{9}^{9}$ El novelista Checo considera que la filosofía ya perdió su capacidad de explotar la existencia humana, genéricamente, y apuesta a que la literatura lo hace mil veces mejor. Para profundizar en dicha argumentación puede leerse la totalidad del libro "El arte de la novela".
} 
En medio de un "desierto que crece". Nietzsche; "donde el conocimiento se ha convertido en información - T. S. Eliot; el proyecto de elucidación filosófica y de creación onto-socio-política de la autonomía" de Castoriadis son la otra voz, otro lenguaje, otro canto esperanzador para la humanidad. Quizá fue por ello que el poeta-ensayista mexicano Octavio Paz, dijo: El pensamiento de la era que comienza -si es que realmente comienza una era- tendrá que encontrar el punto de convergencia entre libertad y fraternidad. Debemos repensar nuestra tradición, renovarla y buscar la reconciliación de las dos grandes tradiciones políticas de la modernidad, el liberalismo y el socialismo. Me atrevo a decir, parafraseando a Ortega y Gasset, que éste es el tema de nuestro tiempo. Me parece que nuestros días son propicios a una empresa de esta envergadura; en algunas obras contemporáneas, por ejemplo en la de Cornelius Castoriadis -advierto ya el comienzo de una respuesta (Paz, 1990, p. 68) $\varphi$

\section{Referencias}

Álvarez, L.P. y Enríquez, G.A. (2016). Imaginario social y representaciones sociales. Teorías sobre el saber cotidiano. Cuernavaca: Universidad Autónoma del Estado de Morelos.

Baronet, B. (2017). Educación para la autonomía y la defensa del territorio En Pensamiento crítico, cosmovisiones y epistemologías otras, para enfrentar la guerra capitalista y construir autonomía. Regaladao, J. (Coord.). México: Universidad de Guadalajara.

Bricmont. J. y Sokal, A. (1999). Imposturas intelectuales. Barcelona: Paidós.

Castoriadis, C. (1983-1989). La Institución Imaginaria de la Sociedad. Barcelona: Tusquest.

Castoriadis, C. (1987). Transformación Social y Creación cultural. Revista Letra Internacional. Madrid: Invierno.

Castoriadis, C. (1993). El Mundo Fragmentado. Buenos Aires: Altamira.

Castoriadis, C. (1997). El Avance de la Insignificancia. Buenos Aires: Eudeba.

Castoriadis, C. (1997). Ontología de la creación. Bogotá: Ensayo-error.

Castoriadis, C. (1998). Los Dominios del Hombre. Barcelona: Gedisa.

Castoriadis, C. (1998). Psique y Sociedad. Bogotá: Ensayo-Error. 
Castoriadis, C. (1999). Figuras de lo Pensable. Valencia: Cátedra.

Castoriadis, C. (2006). Lo que hace Grecia: de Homero a Heráclito. México: Fondo de Cultura Económica.

Castoriadis, C. (2001). El político de Platón. Bogotá: Ensayo-Error.

Castoriadis, C. (2004). Sujeto y verdad en el mundo histórico-social. México: Fondo de Cultura Económica.

Castoriadis, C. (1992). El psicoanálisis: proyecto y Elucidación. Buenos Aires: Nueva Visión.

Castoriadis, C. (2010) Ontología de la Creación. Bogotá: Ensayo y Error.

Cisneros, M. E. (2017). Marxismo, burocracia u opción política: Castoriadis y Laclau-Mouffe. Revista Akademos. 16 (1 y 2), 133-156.

Davies, P. (1996). Dios y la nueva física. Barcelona: Salvat.

Emerson, R. (1963). Hombres Representativos. New York: W. M. Jackson.

Foio, M del S. (2014). Miradas transdisciplinarias en las ciencias sociales en América Latina. Reflexiones que se articulan con los conceptos de autonomía y alteridad desarrollados por Cornelius Castoriadis. Revista de prácticas y discursos, 3(3), 3-24.

Gigon, O. (1971). Los orígenes de la Filosofía Griega. Madrid: Gredos.

Giraldo I, Fabio. (1992). Milán kundera: socialismo, literatura y poder. Bogotá: Minotauro.

Giraldo, F. y Malaver, J. (1997). El Laberinto del Pensamiento y la Creación. Bogotá: Ensayo-Error.

Giraldo, F. (2003). Ciudad y complejidad. Bogotá: Ensayo-Error.

Hegel, W. (1975). Principios de Filosofía del derecho. Buenos Aires: Suramericana. Heidegger, M. (1999). Tiempo y Ser. Madrid: Tecnos.

Heráclito de Éfeso (1970). Fragmentos presocrácticos. Caracas: Universidad Central. Hobsbanwn, E. (1995). Historia del siglo XX. Madrid: Crítica. 
Ibañez, T. (2005). Contra la dominación. Barcelona: Gedisa.

Jaeger, W. (1980). Paideia. México: Fondo de Cultura Económica.

Kant, I. (1961). Crítica de la razón pura. Buenos Aires: Losada.

Mina, W. (2000). Creación Filosófica y Elucidación Política. Revista Ciencias Humanas y Sociales, 4(4), 109-118.

Mina, W. (2003). El pensamiento Afro: Más Allá de Oriente y Occidente. Buenaventura: Universidad del Pacífico.

Mina, W. (2014). La imaginación creadora afrodiaspórica. Cuernavaca: Asociación Iberoamericana de filosofía práctica.

Kundera, M. (1986). El arte de la novela. Barcelona: Tusquest.

Paz, O. (1990). La Otra Voz. Barcelona: Seix Barral.

Platón (1963). Obras Completas. Madrid: Aguilar.

Popper, K. (1985). La Sociedad Abierta y sus Enemigos. Barcelona: Obis.

Popper, K. (1994). El Porvenir Esta Abierto. Barcelona: Paidos.

Popper, K. (1995). La Responsabilidad de Vivir. Barcelona: Paidos.

Wilber, K. (1983). Los Tres ojos del Conocimiento. Barcelona: Kairós.

Wilber, K. (1993). Cuestiones Cuánticas. Escritos místicos de los físicos más famosos. Barcelona: Kaíros.

Wilber, K. (1996). El ojo del espíritu. Barcelona: Kairós. 